\title{
Are Happiness and Life Satisfaction Different Across Religious Groups? Exploring Determinants of Happiness and Life Satisfaction
}

\author{
Kayonda Hubert Ngamaba ${ }^{1} \cdot$ Debbie Soni $^{2}$
}

Published online: 26 September 2017

(C) The Author(s) 2017. This article is an open access publication

\begin{abstract}
This study explores whether different religions experience different levels of happiness and life satisfaction and in case this is affected by country economic and cultural environment. Using World Value Survey (from 1981 to 2014), this study found that individual religiosity and country level of development play a significant role in shaping people's subjective well-being (SWB). Protestants, Buddhists and Roman Catholic were happier and most satisfied with their lives compared to other religious groups. Orthodox has the lowest SWB. Health status, household's financial satisfaction and freedom of choice are means by which religious groups and governments across the globe can improve the SWB of their citizens.
\end{abstract}

Keywords Happiness · Life satisfaction · Religion · Religious differences · Culture

\section{Introduction}

Maximizing citizens' happiness and life satisfaction (i.e. subjective well-being) has been the preferred indicator of social progress (Greve 2010; Stiglitz et al. 2009; Veenhoven 2008), and researchers have suggested many factors that influence subjective well-being (SWB) including religion (Inglehart et al. 2008; Tovar-Murray 2011; Fleche et al. 2011). However, to date, the association between religion and SWB has appeared in a fragmented literature beset with methodological and conceptual difficulties. For example, most studies are limited to just looking at this issue in relation to Christianity and/or only look at one country. The aim of this study is to explore whether different religions experience different

Kayonda Hubert Ngamaba

kayonda.ngamaba@york.ac.uk

1 Department of Social Policy and Social Work, University of York, Heslington, York YO10 5DD, UK

2 School of Business, Education and Social Sciences, Messiah College, 1 College Ave, Mechanicsburg 17055, PA, USA 
levels of happiness and life satisfaction and whether this is affected by country-specific/contextual factors such as cultural and economic environment. This study looks at a large number of different religious groups and across a vast range of countries using data from the World Value Survey. In this study, SWB is presented as a function of happiness and life satisfaction (Diener and Chan 2011; Kahneman and Deaton 2010). Happiness is most closely associated with emotions, feelings or moods (Gustafsson et al. 2009), and life satisfaction is concerned with people's cognitive evaluations and judgements about their life, which might include evaluations of their work and/or personal relationships (Brickman and Campbell 1971; Coburn 2004; Diener et al. 1999).

A positive association between religion/spirituality and people's SWB has been reported in empirical research. Most findings would tend to suggest that a religion/spirituality is of some benefit in terms of people's sense of personal well-being and particularly so in areas such as: expressing emotions (Kim-Prieto and Diener 2009), encouraging good virtues (gratitude, caring and charitable actions) (McCullough et al. 2002), coping with adversity (Fischer et al. 2010), and social connections (Jung 2014) (see Table 1).

Despite a large number of studies reporting a positive association between religion and SWB (see Table 1), questions have been raised about the representativeness of these findings because previous studies have been restricted to few religious groups and withincountry analyses disregarding relevant contextual influences (Eichhorn 2013; Linley et al. 2009; Lobao and Hooks 2003; Lun and Bond 2013). Thus, several authors have called for: (1) a cross-national study of the link between religion and SWB and (2) inclusion into the analyses of national and social contexts (Lun and Bond 2013; Masud and Haron 2008).

Using a large number of different religious groups and across a large range of countries, this study explores whether different religions experience different levels of happiness and life satisfaction and whether this is affected by country-specific/contextual factors such as cultural and economic development. This study replicates the findings across countries using participants from a broad range of religious groups such as Buddhists, Hindus, Jews, Muslims, Christians, Other religious and Nonreligious groups. Moreover, this study investigates the role of variation within some religious groups such as Christian Roman Catholic, Protestant, Orthodox because these subgroups have different traditions and may have different intensity of emotions (Kim-Prieto and Diener 2009; McCullough et al. 2002). On top of affective components (i.e. happiness), this study investigates also the cognitive component (i.e. life satisfaction) in order to get a big and better picture of SWB across religions (Boldt 2006; Brockmann et al. 2009).

The list of major religions selected in this study was drawn from Pew Forum on Religion and comprised: Christians (31.4\% of the world population), Muslims (23.2\%), Hindus (15.0\%), Buddhists (7.1\%), Jews (0.2\%), Other religious groups $(0.8 \%$, e.g. ancestral worshipping) and Nonreligious (16.4\%, e.g. atheist, agnostic, people answering "none" or unaffiliated) (Pew_Research_Center 2015).

It is not easy to define each religious affiliation group, and this study does not intend to do so. Nevertheless, a Christian would be described as someone who believes in the person and ministry of Jesus Christ and who is a member of a Christian denomination. Amongst Christians, three big established groups were investigated: Roman Catholic, Orthodox and Protestants. Roman Catholic members recognize the Pope in the Vatican as the leader of the church and differentiate themselves from Orthodox and Protestants. The Orthodox, also known as Eastern Orthodoxy, identifies its roots in the early Church in Christian Era, and most adherents live in Russia, Eastern Europe and the Middle East. The Protestants are Christians who attempt to reform the Catholic Church in the early sixteenth century. Protestants included people who described themselves as Christian Protestants, Anglicans, 
Table 1 Selected studies investigating the link between religion and subjective well-being (SWB)

\begin{tabular}{|c|c|c|c|}
\hline $\begin{array}{l}\text { Domains } \\
\text { link to } \\
\text { SWB }\end{array}$ & Authors and year & Topic investigated and findings & Targeted group \\
\hline
\end{tabular}

Expressing emotions

Kim-Prieto and
Diener (2009)

McCullough et al. (2002), Metzl (2009)

McCullough et al. (2002), Metzl (2009)

Geschwind et al. (2011)

Lutz et al. (2008)

Sahraian et al. (2013)

Kim-Prieto and Diener (2009)

Rozer and Kraaykamp (2013)

Ferriss (2002)
Religion as a source of variation in the experience of positive and negative emotions: across countries, a study conducted amongst students from 49 nations studying in the USA, reported an association between religion and experience of emotions

Religion is associated with positive affect and well-being; it encourages the experience of certain emotions and discourages other emotions. Protestants Evangelical Christians seek to experience positive emotions at a high intensity compared to Christian Catholics

With their contemplative traditions, Buddhist may be encouraged to seek out emotions that are of low stimulation in their pleasantness

A randomized controlled trial links meditation to positive emotions

Behavioural neuroscience studies on effects of meditation reported an association between greater religiosity and greater neural activation in the brain

Individuals with a more religious attitude experience more happiness

Religion as a source of variation in the experience of positive and negative emotions: across countries, a study conducted amongst students from 49 nations studying in the USA, reported an association between religion and experience of emotions

A higher level of SWB amongst Buddhists and Christians compared to Nonreligious people and people with Other religions

A greater percentage of Protestants who self-report as being "very happy" compared to Catholics or Jews
Christian, Muslim, Hindu, Buddhist and Jewish;

Cross-national: 49 nations

Christian Catholics, Protestants Evangelical Christians

Buddhist

Buddhist

Buddhist

Muslims, Iran

Christian, Muslim, Hindu, Buddhist and Jewish;

Cross-national: 49 nations

Christian, Muslim, Hindu, Buddhist and Jewish; Cross-national

Protestants and Catholics

Christians

Christians

McCullough et al.
Religious environment such as Christian centres can provide a discourse that discourages engagement in unhealthy behaviours (2002)

Christians, for example, encourage a certain attitude in response to the commandment "Love your neighbour"

Ellison and Flannelly (2009), TovarMurray (2011)

Gratitude disposition has been found to be associated with positive affect and wellbeing, prosocial behaviours and traits, and religiousness/spirituality
Christian Catholics,

Protestants Evangelical Christians 
Table 1 continued

\begin{tabular}{|c|c|c|c|}
\hline $\begin{array}{l}\text { Domains } \\
\text { link to } \\
\text { SWB }\end{array}$ & Authors and year & Topic investigated and findings & Targeted group \\
\hline
\end{tabular}

Lyubomirsky and Extraverted are happier, less depressed and Layous (2013), more willing to express gratitude than Senf and Liau neurotic

\section{(2013)}

Tovar-Murray (2011)

Coping with adversity

Fischer et al. (2010)

Metzl 2009)

Chatters et al. (2011), Wells et al. (2012)

Social connections and attendance

Mochon et al. (2011)

Ellison and Flannelly (2009)

Inglehart et al. (1992)

Tewari et al. (2012)

Levin (2013)

Jung (2014)
A positive association between religious behaviours, spiritual beliefs, marital satisfaction, health and happiness amongst Jewish, Roman Catholics and Protestants in the USA

Study reported a variation in well-being of Muslims and Christians due to the way these faith groups cope with adversity and stressful events. While Muslims were significantly more likely to seek social support from family, Christians were more likely to use intrapersonal coping strategies

Religiosity increases resilience after a natural disaster (Hurricane Katrina)

Religious belief might decrease the risk of stress, depression and suicidal thoughts

While passionate believers benefit from their involvement, those with weaker beliefs are actually less happy than those who do not ascribe to any religionatheists and agnostics

A prospective nationwide study of AfricanAmerican adults indicated that religious involvement is negatively associated with depression

As institutions, religiosity may provide a support network

Hindus' participation in a long-duration mass gathering (such as a pilgrimage event) impacts well-being

Participation in synagogue activities was found to be significantly associated with less depression, better quality of life and more optimism

Although the effect size is relatively small, religious attendance is associated with a higher level of happiness in South Korea. However, this positive effect holds only for women and only for Protestants
Jewish, Roman Catholics and Protestants, USA

Muslims and Christians

Christians

Christians

Christians, USA

Christians, USA

Christians

Hindu, India

Jews, Israel

Protestants, Buddhists and Other Religions 
Evangelical, Pentecostal, and so on. Muslims are those who believe in the teachings of Mohammad as a messenger of Allah; this group includes Shia and Sunni. A Buddhist supports the subscription to the Middle Way in accordance with what is outlined by Buddha in order to eventually achieve Enlightenment or Buddhahood as the goal. For the Hindu, however, adherence to the concepts of Hinduism, for example, is required in order for the devotee to achieve the all important Moksha and release from the Samsara cycle. Jews may describe themselves as people who trace their origins to the ancient Hebrew people of Israel and being part of a cultural community in which Judaism is the religion. While Hindus acknowledge multiple gods, Judaism, Christianity and Islam are in someway monotheistic religions (Pew_Research_Center 2015).

\section{Method}

\section{Data Source}

This study investigated the variability in happiness and life satisfaction across religious groups (Buddhists, Hindus, Jews, Muslims, Christians, Other Religious, and Nonreligious) using data from the World Value Survey (WVS). From 1981 to 2014, in collaboration with a European Values Study (EVS), the WVS carried out representative national surveys of more than 330,319 participants in 100 countries, using a common questionnaire to understand changing values and their impact on social and political life. In order to monitor these changes, the WVS executed six different surveys (1981-1984, 1989-1993, 1994-1999, 1999-2004, 2005-2007, 2010-2014) which in total, spanned approximately 33 years, that is from 1981 to 2014 (World-Values-Survey 2015). With an average of 1417 respondents, ranging from 240 to 3531 individuals, participants of each country were selected at random within the representative sample and interviewed face-to-face by a local field organization and supervised by WVS's academic researchers (World-Values-Survey 2015). The ages ranged from 16 to 99 years with a mean of 42.28 years and standard deviation of 16.73. Pooled sample of all six waves of the WVS was verified, and a listwise deletion was applied to deal with missing data (Snijders and Bosker 2012); however, the complete cases represent a good percentage of more than $95 \%$. For example, the happiness variable had some responses treated as missing data such as Don't know (0.90\%), No answer $(0.27 \%)$, Not asked in survey $(1.16 \%)$, Missing or Unknown $(0.01 \%)$; the complete cases used for the happiness variable was $97.6 \%$. Variables were scaled so that higher values reflected more of the positive characteristics. Nevertheless, because this study looked at a range of potential determinants of happiness and life satisfaction, the numbers of respondents were often lower due to missing data on some questionnaire items of interest.

Beside the main survey (i.e. World Value Survey); this study also used data taken from widely known sources that were combined with the main survey. Contextual influences are important in studies of religions across countries because religious people belong to countries where regional and national socio-economic and cultural factors apply. This study used GDP per capita drawn from the World Bank (World-Bank 2015), the Human Development Index (HDI) drawn from United Nations Development Programme (UNDP 2015), the Government Restrictions Index (GRI) and Social Hostilities Index (SHI) drawn from Pew Research Center (Pew_Research_Center 2015). 


\section{Measures}

\section{Dependent Variables: Happiness and Life Satisfaction}

This study used both common reliable SWB, namely happiness and life satisfaction. The combination of affective and cognitive components comes closest to people's everyday experience and captures SWB better than one single item (Diener et al. 1999; Kahneman and Deaton 2010).

Happiness was assessed using a self-report scale 1-4 statement: taking all things together, would you say you are: On a scale of $1-4$ if $1=$ not at all happy; $2=$ not very happy; 3 = quite happy; and $4=$ very happy.

Life satisfaction was assessed using a self-report scale 1-10 question: "All things considered, how satisfied are you with your life as a whole these days?", where "1" stands for "very dissatisfied" and "10" stands for "very satisfied".

\section{Independent Variables}

Religious affiliation group Participants were asked to give the name of the religious denomination into which they belonged, and those who were not believers or affiliated to any religious groups selected Nonreligious. Dummy variable for each religious group was created (e.g. $1=$ Muslim and $0=$ otherwise). (See "Appendix 2" for the list of religious groups by country).

Scale of incomes 1 indicating the lowest income group, 2 the middle-income group, and 3 the highest income group in the country. "We would like to know in what group your household is, counting all wages, salaries, pensions and other incomes that comes in". A dummy variable was created here and below for socio-economic factors (e.g. $1=$ lowincome scale and $0=$ otherwise).

Employment status Full time, Part time, Self-employed, Retired, Housewife, a Student, Unemployed or part of some other employment category.

Highest educational attainment level Participants were asked to indicate their highest educational attainment level: from elementary, secondary to degree level.

Socio-demographic factors age group (i.e. 15-24, 25-34, 35-44, 45-54, 55-64, 65 and over), gender (i.e. men $=0$, women $=1$ ), marital status (i.e. married, living together, divorced, separated, widowed, single).

Household's financial satisfaction was measured using the question: How satisfied are you with the financial situation of your household? ( 1 = completely dissatisfied and $10=$ completely satisfied).

Preference for income inequality Respondents were asked to choose " 1 : if they wanted incomes to be made more equal" and "10: if they needed larger income differences as incentives".

State of health All in all, how would you describe your state of health these days? If $1=$ very poor, $2=$ poor, $3=$ fair, $4=$ good and $5=$ very good.

Freedom of choice and control over life How much freedom of choice and control do you feel you have over the way your life turns out? $(1=$ none at all and $10=$ a great deal $)$.

Trust "Generally speaking, would you say that most people can be trusted or that you need to be very careful in dealing with people?" The answer options were as follows: $0=$ can't be too careful or $1=$ most people can be trusted. 
The importance of friends, family and leisure indicates how important friends/leisure are in your life ( $1=$ not at all important, $4=$ very important $)$.

Attendance to religious services "Apart from Weddings, Funerals and Christenings, how often do you attend religious services? $1=$ never, $2=$ once a year or less, $3=$ on special holidays, $4=$ once a month, $5=$ every week". A dummy variable was created (e.g. every week $=1$ and $0=$ otherwise).

Importance of God "How important is God in your life?" $1=$ not important at all and $10=$ very important. Note The question about the "importance of God" could be worded differently for certain groups that are not monotheistic, such as the Hindus.

Religious person (a person who manifests devotion to a deity): "Independently of whether you attend religious services or not, would you say you are: 1. A religious person, 2. Not a religious person, 3. An atheist".

At country or aggregate level, this study controlled for GDP per capita, government restrictions to religions, social hostilities and geographical regions. For example, previous studies suggested that rich nations were happier than poor nations and that in the long run, the impact of growth was not significant (Easterlin 1974; Inglehart et al. 2008).

GDP per capita the sum of gross value added by all resident producers in the economy, plus any product taxed and lowered any subsidies not included in the value of the products (in current US dollars) (World-Bank 2015).

Human Development Index (HDI) drawn from the UNDP ranges from 0 to 1 , with 0 indicating the lowest level of development and 1 the highest level of human development (UNDP 2015).

The GRI (government restrictions index), ranging from 0 to 10 , with 10 indicating the highest level of government restrictions to religious practices or beliefs and 0 indicating the lowest level (Pew_Research_Center 2015).

The SHI (social hostilities index) also ranging from 0 to 10 , with 10 indicating the highest level of social hostilities involving religion in a society and 0 indicating the lowest level (Pew_Research_Center 2015).

Geographical regions (1) Western Europe, (2) Eastern Europe and Former Soviet Union, (3) North America, (4) Latin America, (5) Asia, (6) sub-Saharan Africa, (7) Middle East and North Africa and (8) Australia. A dummy variable was created (e.g. Western Europe $=1$ and $0=$ otherwise) and tested the interaction between religious groups and different regions.

\section{Analysis}

Using Stata 13.1 software (Stata 2013), this study explores the variability in happiness and life satisfaction across religious groups and whether the variability is affected by countryspecific/contextual factors such as cultural and economic development. Nine religious groups were investigated: Buddhist, Hindu, Jew, Muslim, Roman Catholic, Orthodox, Protestant, Other religions and Nonreligious. Before to run the multilevel mixed-effects regression analysis, the one-way analysis of variance (ANOVA) was used to determine whether there are any significant differences between the means of these religious groups.

A multilevel mixed-effects regression analysis (xtmixed Stata's command) was used because WVS executed six different surveys from 1981 to 2014 (Snijders and Bosker 2012; Torres-Reyna 2014). The multilevel analysis methodology allows studying effects that vary by entity and estimates group level averages. This is important because the regular regression ignores the average variation between entities (Snijders and Bosker 2012). The mixed-effects analysis allows a wide variety of correlation patterns to be 
explicitly modelled. In this study, individuals who were affiliated to religious groups were nested by country (see Fig. 1) (Snijders and Bosker 2012).

The Models 1 and 2 were constructed for each dependent variable (i.e. happiness and life satisfaction). Correlations amongst variables were tested prior to analysis because highly correlated predictors might lead to multicollinearity and the last model of multivariate might be subject to suppressor effects or other statistical artefacts (Miller and Chapman 2001; Smith et al. 1992). There was no evidence of multicollinearity amongst the measured variables. Model 1 was the starting point where all religious groups were included without controlling for any independent variables. At this stage, the interaction between religion and geographical regions was tested. Model 2 extends Model 1 by controlling for covariates.

Variables used in this study were measured at different scales; thus, standardization procedures were applied to know which of the explanatory variables have a greater effect on happiness and life satisfaction. The thumb's effect sizes (Cohen 1992) $r \leq .10$ was used as a "small" effect size, $r>.10$ and $\leq .30$ as a "medium" effect size, and $r>.30$ as a "large" effect size. The level of significance was: $p<.001 ; p<.01 ; p<.05$, and nonsignificant otherwise.

\section{Results}

This study explored the variability in happiness and life satisfaction across main religious groups: Buddhist, Hindu, Jew, Muslim, Roman Catholic, Orthodox, Protestant, Other religions and Nonreligious. The average happiness (on a scale of 1 to 4) was slightly higher amongst Protestants $(\mathrm{M}=3.21, \mathrm{SD}=0.72)$, followed by Buddhist $(\mathrm{M}=3.17$, $\mathrm{SD}=0.63)$, Other religions $(\mathrm{M}=3.17, \mathrm{SD}=0.72)$, Roman Catholic $(\mathrm{M}=3.13$, $\mathrm{SD}=0.72)$, Jew $(\mathrm{M}=3.06, \mathrm{SD}=0.73)$, Hindu $(\mathrm{M}=3.05, \mathrm{SD}=0.78)$, Muslim $(\mathrm{M}=3.03, \mathrm{SD}=0.76)$, Nonreligious $(\mathrm{M}=3.02, \mathrm{SD}=0.71)$ and finally, Orthodox $(\mathrm{M}=2.72, \mathrm{SD}=0.76)$ with the lowest happiness. There was a significant effect of

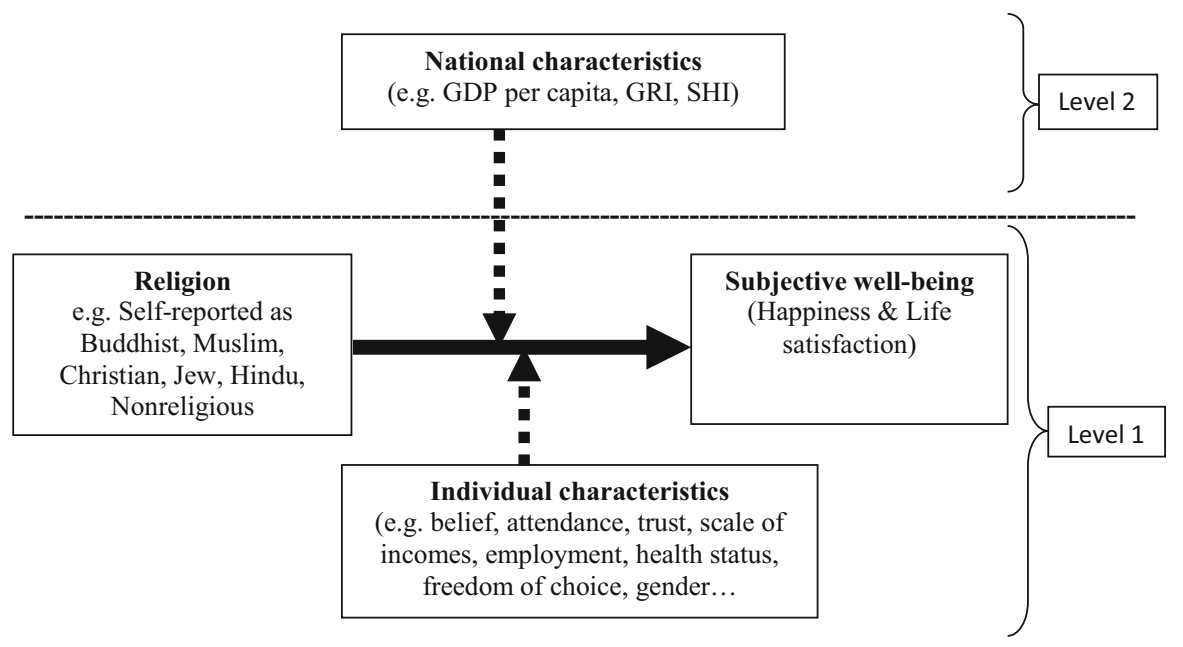

Fig. 1 Visual representation of theoretical multilevel structure investigating the variability in happiness and life satisfaction across religions 
Table 2 Multilevel mixed-effects regression analysis of happiness and life satisfaction across religious groups. Source: World-Values-Survey (2015)

\begin{tabular}{|c|c|c|c|c|c|c|}
\hline & \multicolumn{3}{|l|}{ Happiness } & \multicolumn{3}{|c|}{ Life satisfaction } \\
\hline & Coef. (B) & Std. Err. & $p$ value & Coef. (B) & Std. Err. & $p$ value \\
\hline Buddhist & 0.001 & 0.003 & 0.651 & -0.002 & 0.003 & 0.470 \\
\hline Hindu & 0.002 & 0.003 & 0.521 & 0.009 & 0.003 & 0.004 \\
\hline Jew & -0.001 & 0.003 & 0.843 & 0.000 & 0.002 & 0.941 \\
\hline Muslim & 0.013 & 0.006 & 0.046 & -0.009 & 0.006 & 0.096 \\
\hline Roman Catholic & 0.010 & 0.006 & 0.095 & -0.001 & 0.005 & 0.925 \\
\hline Protestant & 0.023 & 0.005 & 0.000 & 0.008 & 0.005 & 0.073 \\
\hline Orthodox & -0.001 & 0.005 & 0.776 & -0.003 & 0.004 & 0.528 \\
\hline Other religious & 0.006 & 0.003 & 0.031 & 0.004 & 0.002 & 0.083 \\
\hline Nonreligious & 0.012 & 0.005 & 0.027 & 0.001 & 0.005 & 0.770 \\
\hline Full time & -0.017 & 0.007 & 0.019 & 0.002 & 0.006 & 0.786 \\
\hline Part time & -0.006 & 0.004 & 0.181 & -0.001 & 0.004 & 0.766 \\
\hline Self-employed & -0.013 & 0.005 & 0.007 & -0.003 & 0.004 & 0.483 \\
\hline Retired & 0.000 & 0.005 & 0.946 & 0.002 & 0.005 & 0.718 \\
\hline Housewife & 0.010 & 0.006 & 0.085 & 0.014 & 0.005 & 0.005 \\
\hline Students & 0.005 & 0.004 & 0.277 & 0.011 & 0.004 & 0.005 \\
\hline Unemployed & -0.031 & 0.005 & 0.000 & -0.018 & 0.004 & 0.000 \\
\hline Other employment & 0.002 & 0.003 & 0.404 & 0.001 & 0.002 & 0.635 \\
\hline Elementary education & -0.010 & 0.004 & 0.005 & 0.004 & 0.003 & 0.252 \\
\hline Secondary education & -0.010 & 0.004 & 0.015 & 0.003 & 0.004 & 0.466 \\
\hline University education & -0.010 & 0.004 & 0.004 & 0.005 & 0.003 & 0.100 \\
\hline Gender (female) & 0.023 & 0.002 & 0.000 & 0.020 & 0.002 & 0.000 \\
\hline Married & 0.079 & 0.022 & 0.000 & 0.028 & 0.019 & 0.144 \\
\hline Together & 0.023 & 0.011 & 0.030 & 0.010 & 0.009 & 0.317 \\
\hline Divorced & -0.013 & 0.008 & 0.094 & -0.010 & 0.007 & 0.185 \\
\hline Separated & -0.013 & 0.006 & 0.031 & -0.011 & 0.005 & 0.040 \\
\hline Widowed & -0.018 & 0.011 & 0.087 & -0.008 & 0.009 & 0.375 \\
\hline Single & -0.005 & 0.019 & 0.773 & -0.017 & 0.017 & 0.327 \\
\hline Age $16-24$ & 0.041 & 0.018 & 0.025 & 0.006 & 0.016 & 0.703 \\
\hline Age $25-34$ & 0.015 & 0.020 & 0.452 & -0.012 & 0.018 & 0.504 \\
\hline Age $35-44$ & 0.001 & 0.019 & 0.946 & -0.021 & 0.017 & 0.220 \\
\hline Age $45-54$ & -0.002 & 0.017 & 0.892 & -0.017 & 0.015 & 0.276 \\
\hline Age $55-64$ & 0.004 & 0.015 & 0.784 & -0.005 & 0.014 & 0.722 \\
\hline Age 65-over & 0.017 & 0.014 & 0.242 & 0.001 & 0.013 & 0.923 \\
\hline Low-income scale & -0.026 & 0.004 & 0.000 & -0.017 & 0.003 & 0.000 \\
\hline Middle-income scale & 0.001 & 0.003 & 0.707 & 0.006 & 0.003 & 0.044 \\
\hline High-income scale & 0.006 & 0.003 & 0.071 & 0.015 & 0.003 & 0.000 \\
\hline Financial satisfaction & 0.175 & 0.002 & 0.000 & 0.385 & 0.002 & 0.000 \\
\hline Inequality preferences & 0.003 & 0.002 & 0.094 & 0.011 & 0.002 & 0.000 \\
\hline State of health & 0.262 & 0.002 & 0.000 & 0.141 & 0.002 & 0.000 \\
\hline Freedom of choice & 0.091 & 0.002 & 0.000 & 0.197 & 0.002 & 0.000 \\
\hline Meaning of life & 0.005 & 0.002 & 0.007 & -0.012 & 0.002 & 0.000 \\
\hline
\end{tabular}


Table 2 continued

\begin{tabular}{|c|c|c|c|c|c|c|}
\hline & \multicolumn{3}{|l|}{ Happiness } & \multicolumn{3}{|c|}{ Life satisfaction } \\
\hline & Coef. (B) & Std. Err. & $p$ value & Coef. (B) & Std. Err. & $p$ value \\
\hline National pride & 0.082 & 0.002 & 0.000 & 0.047 & 0.002 & 0.000 \\
\hline Trust & 0.021 & 0.002 & 0.000 & 0.017 & 0.002 & 0.000 \\
\hline Friends important & 0.036 & 0.002 & 0.000 & 0.013 & 0.002 & 0.000 \\
\hline Family important & 0.048 & 0.002 & 0.000 & 0.024 & 0.002 & 0.000 \\
\hline Leisure important & 0.041 & 0.002 & 0.000 & 0.013 & 0.002 & 0.000 \\
\hline Weekly Rel. attend & 0.020 & 0.006 & 0.001 & 0.016 & 0.005 & 0.002 \\
\hline Monthly attend & 0.002 & 0.004 & 0.671 & 0.003 & 0.004 & 0.428 \\
\hline Special days attend & -0.001 & 0.005 & 0.835 & 0.007 & 0.004 & 0.092 \\
\hline Yearly attend & -0.003 & 0.005 & 0.457 & 0.005 & 0.004 & 0.186 \\
\hline Never attend & 0.002 & 0.005 & 0.726 & 0.015 & 0.004 & 0.001 \\
\hline Importance of God & 0.013 & 0.003 & 0.000 & 0.040 & 0.002 & 0.000 \\
\hline Religious person & -0.021 & 0.002 & 0.000 & -0.008 & 0.002 & 0.000 \\
\hline GDP & -0.052 & 0.007 & 0.000 & -0.052 & 0.006 & 0.000 \\
\hline Gini coefficient & -0.052 & 0.006 & 0.000 & -0.045 & 0.005 & 0.000 \\
\hline HDI & -0.090 & 0.018 & 0.000 & 0.024 & 0.014 & 0.096 \\
\hline GRI & 0.054 & 0.012 & 0.000 & 0.046 & 0.010 & 0.000 \\
\hline SHI & 0.007 & 0.008 & 0.393 & -0.019 & 0.007 & 0.007 \\
\hline Western Europe & 0.215 & 0.241 & 0.372 & 0.134 & 0.150 & 0.373 \\
\hline Eastern Europe & -0.213 & 0.248 & 0.390 & -0.177 & 0.155 & 0.251 \\
\hline North America & 0.281 & 0.302 & 0.353 & 0.079 & 0.188 & 0.674 \\
\hline Latin America & 0.131 & 0.260 & 0.614 & 0.161 & 0.162 & 0.322 \\
\hline Asia & -0.007 & 0.261 & 0.979 & -0.069 & 0.162 & 0.669 \\
\hline Africa & -0.313 & 0.262 & 0.233 & -0.344 & 0.165 & 0.036 \\
\hline Middle east & -0.383 & 0.264 & 0.147 & -0.251 & 0.165 & 0.127 \\
\hline Australia & 0.206 & 0.302 & 0.496 & 0.058 & 0.188 & 0.758 \\
\hline Intercept & -0.170 & 0.253 & 0.502 & 0.158 & 0.157 & 0.316 \\
\hline $\mathrm{N}$ & 237,443 & & & & & \\
\hline
\end{tabular}

Standardized variables; significant $p<.001, .01, .05$

religion on happiness at the $p<.05$ level for the different religious groups $[\mathrm{F}(8$, $316630)=1299.72, \mathrm{p}=0.001]$.

A similar pattern was seen for life satisfaction. The average life satisfaction (on a scale of 1 to 10$)$ was slightly higher amongst Roman Catholics $(\mathrm{M}=7.12, \mathrm{SD}=2.31)$, followed by Protestant $(\mathrm{M}=7.07, \mathrm{SD}=2.33)$, Other religions $(\mathrm{M}=6.97, \mathrm{SD}=2.26)$, Buddhist $(\mathrm{M}=6.88, \mathrm{SD}=2.00)$, Jew $(\mathrm{M}=6.85, \mathrm{SD}=2.23)$, Nonreligious $(\mathrm{M}=6.62$, $\mathrm{SD}=2.30)$, Hindu $(\mathrm{M}=6.23, \mathrm{SD}=2.50)$, Muslim $(\mathrm{M}=6.16, \mathrm{SD}=2.55)$ and finally, Orthodox $(M=5.43, S D=2.49)$ with the lowest life satisfaction. There was a significant effect of religion on life satisfaction at the $p<.05$ level for the different religious groups $[\mathrm{F}(8,319261)=2059.44, \mathrm{p}=0.001]$. Amongst all religious groups, Orthodox had the lowest SWB. The correlations, tested prior to analysis, suggest a negative association between Orthodox and both happiness and life satisfaction $(r=-0.144, r=-0.155$, 
$p<0.01$, respectively) (See "Appendix 1" for correlation between happiness, life satisfaction and other variables).

Table 2 presents the results of the multilevel mixed-effects regression analysis of happiness and life satisfaction. The results related to happiness are presented on the left, and those related to life satisfaction are presented on the right of Table 2 .

In terms of happiness, the multilevel analysis showed a positive association with being protestant, female, married, younger (16 to 24 years old), household's financial satisfaction, state of health, freedom of choice, national pride, trust, importance of friends, family and leisure, weekly religious attendance and importance of God. On the other hand, being unemployed and in low-income scale groups were negatively associated with happiness.

With regard to life satisfaction, a similar trend has been observed. The multilevel analysis showed a positive association with being female, household's financial satisfaction, state of health, freedom of choice, national pride, trust, importance of friends, family and leisure, weekly religious attendance and importance of God. On the other hand, being unemployed, in low-income scale groups and meaning of life were negatively associated with life satisfaction.

Nevertheless, according to Cohen's rules of thumb (Cohen 1992) only three factors were above the "small" effect size $(>0.10)$. State of health, household's financial satisfaction and freedom of choice showed "medium" effect sizes and were positively associated with happiness and life satisfaction.

\section{Discussion}

This study explores whether different religions experience different levels of happiness and life satisfaction and in case this is affected by country-specific/contextual factors such as economic and cultural environment.

In terms of happiness, individuals who described themselves as Protestants and Buddhists were characterized by high experiences of happiness compared to any other groups. With regard to life satisfaction, Roman Catholics, Protestants and Buddhists were more satisfied with their lives than any other groups. On the other hand, those who described themselves as Orthodox were less happy and less satisfied with their lives compared to any other group. Variability in happiness and life satisfaction across religious groups has been supported empirically, despite the fact that some religious groups have never been investigated across countries. For example, our results reported higher levels of happiness and life satisfaction amongst Protestants compared to other religious groups, as some cross-national studies have stated (Ferriss 2002; Rozer and Kraaykamp 2013). This study found differences in happiness between Protestants and Roman Catholics. Emotional wellbeing seems to be more prominent amongst Protestants rather than Roman Catholics. In line with previous studies, Christian Protestants seek to experience positive emotions at a high intensity compared to Christian Catholics (Ferriss 2002; Metzl 2009). Nevertheless, with regard to life satisfaction, both Protestants and Roman Catholics were equally satisfied with their lives. Our results found that Protestants were not the only people to be characterized by higher levels of happiness and life satisfaction, but these levels could be found in women, who have higher religious attendances amongst Protestants. These findings may explain why a positive association between attendance to religious services and happiness has been found in women and Protestants in South Korea but not amongst Buddhists, Catholics and other religious groups (Jung 2014). 
Our results demonstrated that within the Christian faith, people who described themselves as Orthodox were characterized by lower levels of happiness and life satisfaction compared to Nonreligious and any other religious groups. An important question has been asked in the literature, can people's religiosity make them really happier or are they happier because they belong to a happy nation or their happiness through religiosity can mainly be derived through conforming to the standard in their country (Eichhorn 2013; Linley et al. 2009; Lobao and Hooks 2003; Lun and Bond 2013)? Our results provide empirical support suggesting that religiosity and country level of development both play an important role in shaping people's happiness and life satisfaction. For example, religious members living in developed regions such as Western Europe, North America and Australia were happier and more satisfied with their lives than those living in less developed regions such as Eastern Europe, Africa and the Middle East. Interestingly, people who describe themselves as Orthodox were less happy and less satisfied with their lives and were mainly located in Eastern Europe and Former Soviet Union. Nevertheless, with the same GDP per capita, people living in Latin America are happier and more satisfied with their lives than people living in Eastern Europe. Living in Latin America, a region traditionally Roman Catholic and Protestant might explain the high levels of happiness and life satisfaction compared to Eastern Europe where the collapse of communism has left a spiritual vacuum (Inglehart et al. 2008). Without a doubt, this argument is challenged with surveys of China and Vietnam, suggesting that despite the remaining presence of communist parties, those countries enjoy high economic growth and might show, in the long run, an increase in SWB than Eastern Europe (Knight and Gunatilaka 2010). While further research needs to investigate the underlying cause of low levels of happiness and life satisfaction amongst Orthodox, our study found that Orthodox living in Eastern Europe self-reported lower levels of happiness and life satisfaction compared to Orthodox living in Latin America. In line with previous studies, this may suggest that there are differences in the experience of happiness and life satisfaction across different religious groups (KimPrieto and Diener 2009). On the other hand, country level of development plays an important role in shaping people's SWB (Howell and Howell 2008).

The most significant factors driving happiness and life satisfaction include state of health, household's financial satisfaction, income ranking position, unemployment, freedom of choice, national pride, trust, importance of friends, family, leisure, being a female and weekly religious attendance (see Table 2). Nevertheless, when the Cohen's rules of thumb (Cohen 1992; Wright 1992) was applied, most factors seem to have "small" effect size $(r \leq 0.10)$. Thus, the most significant factors driving happiness and life satisfaction were state of health, household's financial satisfaction and freedom of choice.

Health status is positively associated with higher happiness and life satisfaction. In line with previous studies, good health is associated with greater well-being, while setbacks in health have negative effects on happiness and life satisfaction. For example, people who have painful chronic conditions and those who become seriously disabled have permanently lower levels of SWB compared to their counterparts who are not disabled (Headey 2010). Our multilevel analysis showed a positive association between health status and both happiness and life satisfaction even after controlling for several factors including GDP per capita, relative income, psychological factors, socio-economic and demographic factors (Miret et al. 2014; Fleche et al. 2011). Thus, improving people's health status is one means by which governments across the globe can improve the subjective well-being (SWB) of their citizens.

This study found that the magnitude of the association between household's financial satisfaction and SWB was medium, positive and significantly stronger amongst different 
religious groups. The results on household's financial satisfaction support the "need theory" as a universal approach across religions and suggest that income not only allows individuals to purchase goods and services (Howell and Howell 2008), but it also goes hand in hand with happiness and life satisfaction ( $\mathrm{Ng}$ and Diener 2014). Absolute and mostly relative income plays an important role in influencing happiness and life satisfaction (Boyce et al. 2010; Easterlin 1974, 2005). If GDP per capita can no longer be used as the best indicator of people's living standard (Stiglitz et al. 2009), being in a country where basic needs (e.g. health, education and income indispensable for a decent standard of living) are provided plays an important role in shaping people's SWB (Inglehart et al. 2008).

Emancipative values such as freedom of choice, gender equality and tolerance have been associated with life satisfaction (Inglehart et al. 2008). Everybody shall have the right to freedom of choice including freedom to have, to adopt a religion or to express feelings and emotions. Religious groups that promote good values such as freedom of choice, freedom of emotions, gratitude, and social connections may improve the SWB of their members (Fischer et al. 2010; Jung 2014; Kim-Prieto and Diener 2009).

It is important to recognize four limitations of this research. First, all variables used in this study were measured by single items. Although researchers have used the same singleitem happiness (Inglehart et al. 2008; Lun and Bond 2013), it is important to replicate the current findings with better-validated multi-item scales (Fisher et al. 2016). Second, this study examined as much as possible explanatory variables including socio-cultural and demographic factors, but there might be other important factors that were not measured in this study. Third, this research reported that people from some religious groups, such as Orthodox, were less happy and less satisfied with their lives, further studies are encouraged to investigate the underlining causes. Also, further work must be done to expand the research of subgroups of certain of these religious groups such as: Sunnis and Shia Muslims, Messianic Jews.

In conclusion, by investigating the variability in happiness and life satisfaction across a large number of religious groups, this study has provided empirical support suggesting that religiosity and country level of development both play a significant role in shaping the SWB of people. Religious groups that promote good values such as freedom of choice, freedom of emotions, gratitude and social connections may improve the SWB of their members. Health status, household's financial satisfaction and freedom of choice are means by which governments across the globe can improve the subjective well-being of their citizens.

Acknowledgements The authors thank Professor Chris Armitage and Dr Maria Panagioti for their help and support with this study and the reviewers for their useful comments on the manuscript.

\section{Compliance with Ethical Standards}

Conflict of interest The authors declare that they have no conflict of interest.

Open Access This article is distributed under the terms of the Creative Commons Attribution 4.0 International License (http://creativecommons.org/licenses/by/4.0/), which permits unrestricted use, distribution, and reproduction in any medium, provided you give appropriate credit to the original author(s) and the source, provide a link to the Creative Commons license, and indicate if changes were made.

\section{Appendix 1}

See Table 3. 
Table 3 Correlation between happiness and life satisfaction and other factors. Source: World-ValuesSurvey (2015)

\begin{tabular}{|c|c|c|}
\hline & Happiness & Life satisfaction \\
\hline Happiness & 1.0000 & \\
\hline Life satisfaction & 0.4704 & 1.0000 \\
\hline Buddhist & 0.0281 & 0.0198 \\
\hline Hindu & $-0.0016 \mathrm{~ns}$ & -0.0266 \\
\hline Jew & $0.0011 \mathrm{~ns}$ & 0.0083 \\
\hline Muslim & -0.0171 & -0.0932 \\
\hline Roman Catholic & 0.0535 & 0.1192 \\
\hline Protestant & 0.0790 & 0.0593 \\
\hline Orthodox & -0.1444 & -0.1555 \\
\hline Other religious & 0.0233 & 0.0233 \\
\hline Nonreligious & -0.0203 & $0.0024 \mathrm{~ns}$ \\
\hline Full time & 0.0248 & 0.0477 \\
\hline Part time & 0.0179 & 0.0209 \\
\hline Self-employed & 0.0197 & -0.0043 \\
\hline Retired & -0.0641 & -0.0248 \\
\hline Housewife & 0.0205 & 0.0143 \\
\hline Students & 0.0453 & 0.0345 \\
\hline Unemployed & -0.0584 & -0.0874 \\
\hline Other employment & -0.0041 & -0.0187 \\
\hline Elementary education & -0.0404 & -0.0491 \\
\hline Secondary education & 0.0237 & -0.0039 \\
\hline University education & 0.0644 & 0.0770 \\
\hline Gender (female) & 0.0077 & 0.0089 \\
\hline Married & 0.0485 & 0.0106 \\
\hline Together & 0.0364 & 0.0458 \\
\hline Divorced & -0.0557 & -0.0371 \\
\hline Separated & -0.0336 & -0.0168 \\
\hline Widowed & -0.0978 & -0.0591 \\
\hline Single & 0.0114 & 0.0049 \\
\hline Age 16-24 & 0.0494 & 0.0317 \\
\hline Age $25-34$ & 0.0274 & $-0.007 \mathrm{~ns}$ \\
\hline Age $35-44$ & 0.0033 & -0.0118 \\
\hline Age $45-54$ & -0.0259 & -0.0181 \\
\hline Age 55-64 & -0.0337 & -0.0054 \\
\hline Age 65-over & -0.0366 & $0.0020 \mathrm{~ns}$ \\
\hline Low-income scale & -0.1427 & -0.1796 \\
\hline Middle-income scale & 0.0506 & 0.0483 \\
\hline High-income scale & 0.1187 & 0.1532 \\
\hline Financial satisfaction & 0.3413 & 0.5606 \\
\hline Inequality preferences & 0.0483 & 0.0551 \\
\hline State of health & 0.3727 & 0.3011 \\
\hline Freedom of choice & 0.2465 & 0.3992 \\
\hline
\end{tabular}


Table 3 continued

\begin{tabular}{|c|c|c|}
\hline & Happiness & Life satisfaction \\
\hline Meaning of life & 0.0378 & $-0.0018 \mathrm{~ns}$ \\
\hline National pride & 0.1633 & 0.1260 \\
\hline Trust & 0.0588 & 0.0754 \\
\hline Friends important & 0.1229 & 0.0866 \\
\hline Family important & 0.1118 & 0.0650 \\
\hline Leisure important & 0.1407 & 0.1280 \\
\hline Weekly Rel. attend & 0.0795 & 0.0292 \\
\hline Monthly attend & 0.0073 & 0.0177 \\
\hline Special days attend & -0.0378 & -0.0395 \\
\hline Yearly attend & -0.0245 & -0.0131 \\
\hline Never attend & -0.0383 & -0.0123 \\
\hline Importance of God & 0.0610 & 0.0320 \\
\hline Religious person & -0.0365 & $-0.0002 \mathrm{~ns}$ \\
\hline GDP & 0.1318 & 0.1823 \\
\hline Gini coefficient & 0.0715 & 0.0434 \\
\hline HDI & 0.0621 & 0.1774 \\
\hline GRI & -0.0790 & -0.1146 \\
\hline SHI & -0.0585 & -0.0997 \\
\hline Western Europe & 0.0569 & 0.1168 \\
\hline Eastern Europe & -0.1975 & -0.1963 \\
\hline North America & 0.0706 & 0.0820 \\
\hline Latin America & 0.0902 & 0.1879 \\
\hline Asia & 0.0384 & 0.0066 \\
\hline Africa & 0.0208 & -0.0888 \\
\hline Middle east & -0.0558 & -0.0867 \\
\hline Australia & 0.0572 & 0.0675 \\
\hline
\end{tabular}

Pairwise correlations, significant $p<.01 ; n s$ non-significant

\section{Appendix 2}

See Table 4. 


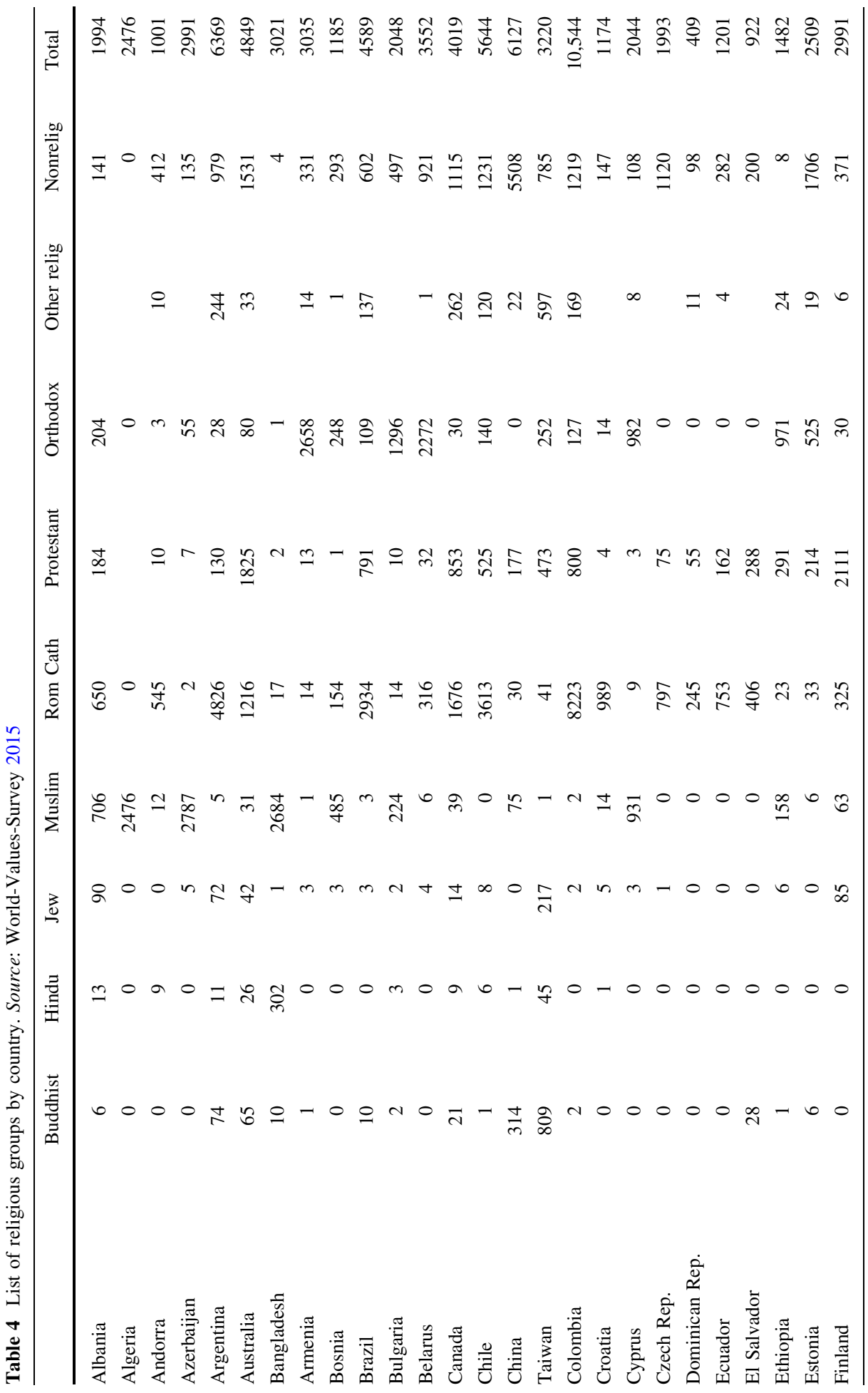




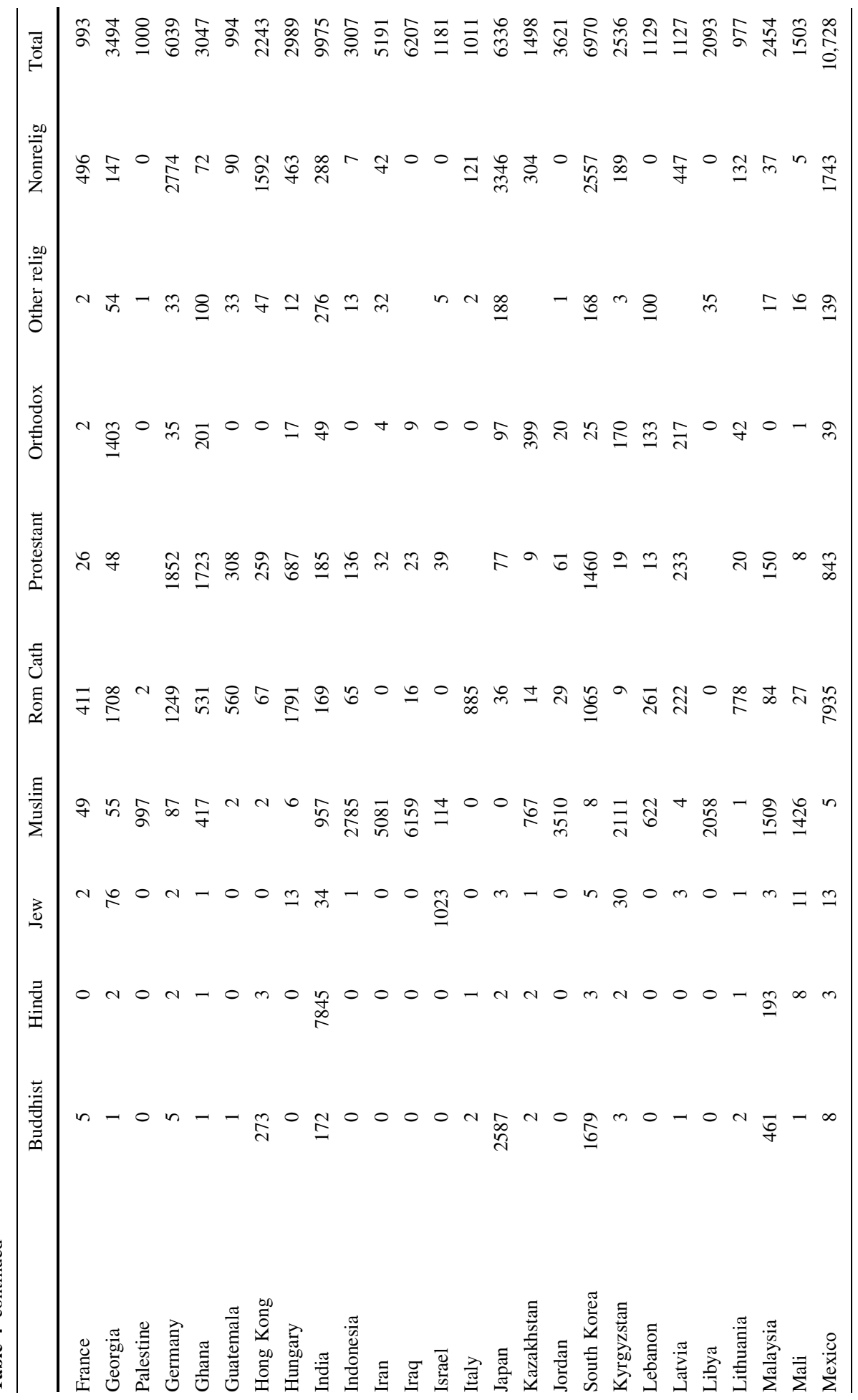




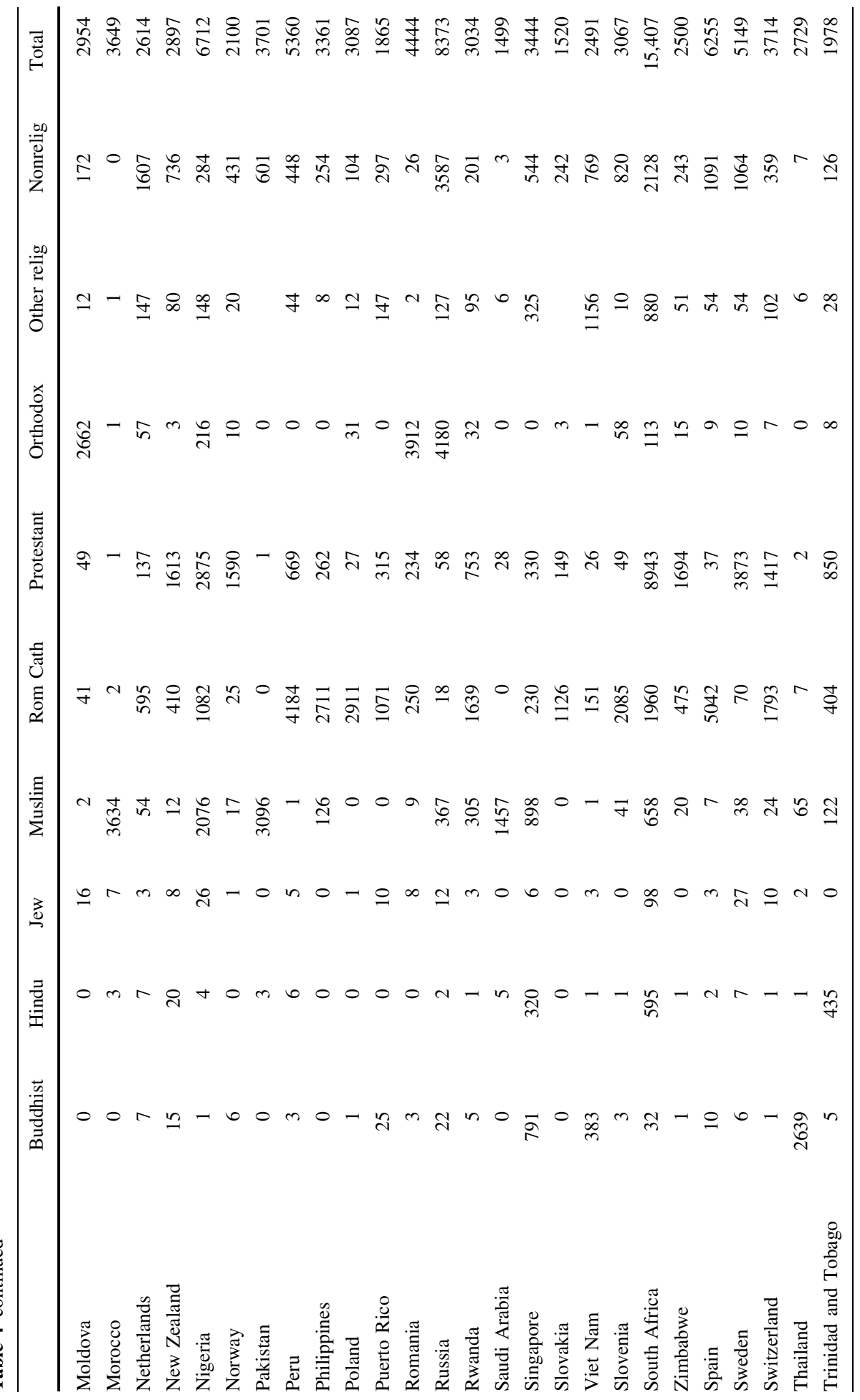




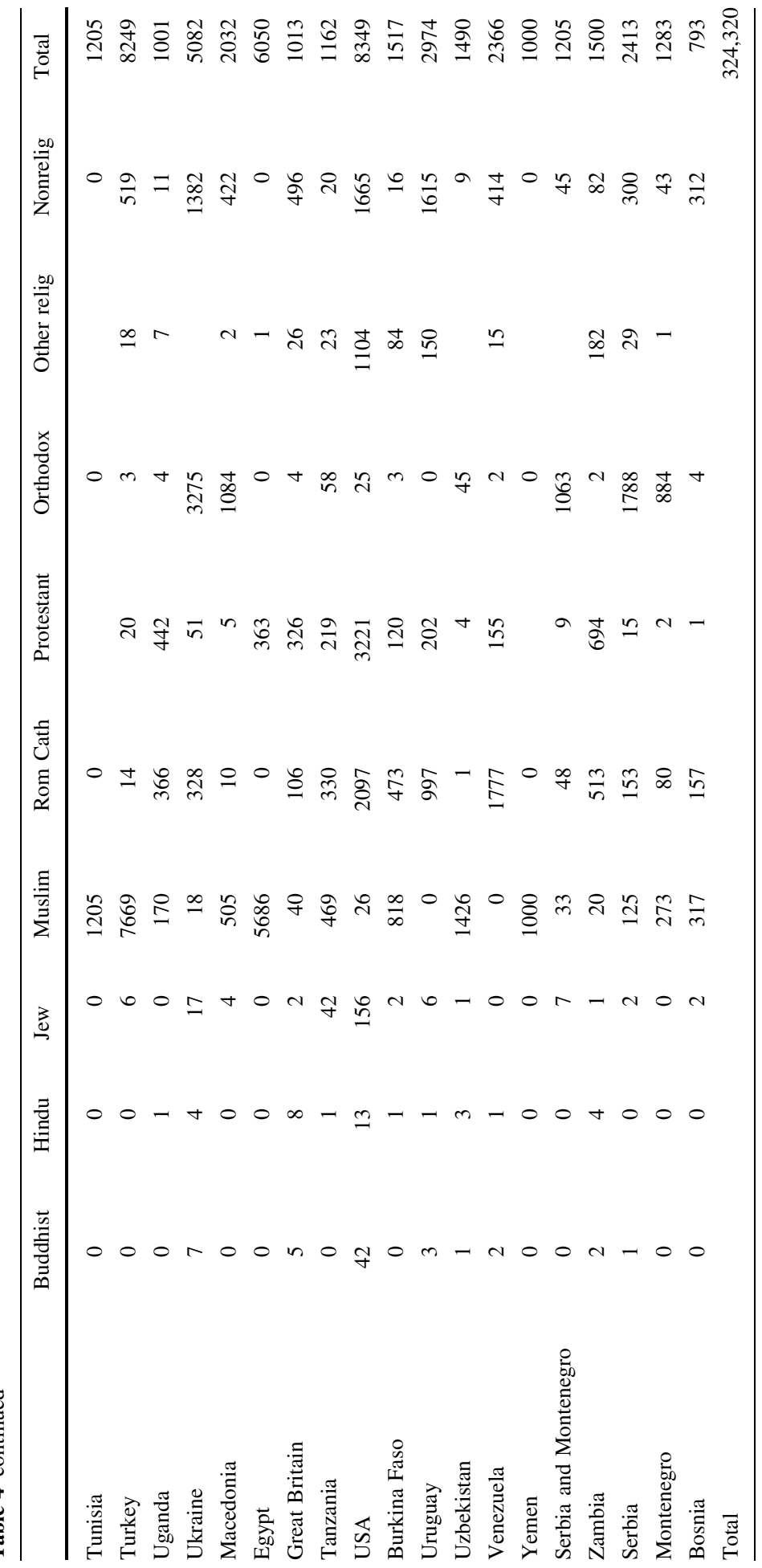




\section{References}

Boldt, J. (2006). Volume therapy in cardiac surgery: Are Americans different from Europeans? [Review]. Journal of Cardiothoracic and Vascular Anesthesia, 20(1), 98-105. doi:10.1053/j.jvca.2005.07.023.

Boyce, C. J., Brown, G. D. A., \& Moore, S. C. (2010). Money and happiness: Rank of income, not income, affects life satisfaction. Psychological Science, 21(4), 471-475. doi:10.1177/0956797610362671.

Brickman, P., \& Campbell, D. T. (1971). Hedonic relativism and planning the good society. In M. H. Appley (Ed.), Adaptation-level theory (pp. 287-305). New York: Academic Press.

Brockmann, H., Delhey, J., Welzel, C., \& Yuan, H. (2009). The China puzzle: Falling happiness in a rising economy. Journal of Happiness Studies, 10(14), 407. doi:10.1007/s10902-008-9095-4.

Chatters, L. M., Mattis, J. S., Woodward, A. T., Taylor, R. J., Neighbors, H. W., \& Grayman, N. A. (2011). Use of ministers for a serious personal problem among african americans: Findings from the national survey of american life. American Journal of Orthopsychiatry, 81(1), 118-127. doi:10.1111/j.19390025.2010.01079.x.

Coburn, D. (2004). Beyond the income inequality hypothesis: Class, neo-liberalism, and health inequalities. Social Science and Medicine, 58(51), 41-56. doi:10.1016/S0277-9536\%2803\%2900159-X.

Cohen, J. (1992). A power primer. Psychological Bulletin, 112(1), 155-159.

Diener, E., \& Chan, M. Y. (2011). Happy people live longer: Subjective well-being contributes to health and longevity. Applied Psychology-Health and Well Being, 3(1), 1-43. doi:10.1111/j.1758-0854.2010. 01045.x.

Diener, E., Suh, E. M., Lucas, R. E., \& Smith, H. L. (1999). Subjective well-being: Three decades of progress. Psychological Bulletin, 125(2), 276-302. doi:10.1037/0033-2909.125.2.276.

Easterlin, R. A. (1974). Does economic growth improve the human lot? Some empirical evidence. In P. A. David \& M. W. Reder (Eds.), Nations and households in economic growth: Essays in honour of Moses Abramovitz. New York: Academic Press.

Easterlin, R. A. (2005). Feeding the illusion of growth and happiness: A reply to Hagerty and Veenhoven. Social Indicators Research, 74(3), 429-443. doi:10.1007/s11205-004-6170-z.

Eichhorn, J. (2013). Unemployment needs context: How societal differences between countries moderate the loss in life-satisfaction for the unemployed. Journal of Happiness Studies, 14(6), 1657-1680. doi:10. 1007/s10902-012-9402-y.

Ellison, C. G., \& Flannelly, K. J. (2009). Religious Involvement and risk of major depression in a prospective nationwide study of African American adults. Journal of Nervous and Mental Disease, 197(8), 568-573. doi:10.1097/Nmd.0b013e3181b08f45.

Ferriss, A. L. (2002). Does material well-being affect non-material well-being? Social Indicators Research, 60(1-3), 275-280. doi:10.1023/a:1021273317425.

Fischer, P., Ai, A. L., Aydin, N., Frey, D., \& Haslam, S. A. (2010). The relationship between religious identity and preferred coping strategies: An examination of the relative importance of interpersonal and intrapersonal coping in Muslim and Christian faiths. Review of General Psychology, 14(4), 365-381. doi:10.1037/A0021624.

Fisher, G. G., Matthews, R. A., \& Gibbons, A. M. (2016). Developing and investigating the use of singleitem measures in organizational research. Journal of Occupational Health Psychology, 21(1), 3-23. doi: $10.1037 / \mathrm{a} 0039139$.

Fleche, S., Smith, C., \& Sorsa, P. (2011). Exploring determinants of subjective well being in OECD countries: Evidence from the world value survey. Paris: OECD Economics Department.

Geschwind, N., Peeters, F., Drukker, M., van Os, J., \& Wichers, M. (2011). Mindfulness training increases momentary positive emotions and reward experience in adults vulnerable to depression: A randomized controlled trial. Journal of Consulting and Clinical Psychology, 79(5), 618-628. doi:10.1037/ a0024595.

Greve, B. (2010). Introduction. In B. Greve (Ed.), Happiness and social policy in Europe (pp. 1-10). Cheltenham, UK: Edward Elgar.

Gustafsson, B., Johansson, M., \& Palmer, E. (2009). The welfare of Sweden's old-age pensioners in times of bust and boom from 1990. Ageing \& Society, 29(24), 539. doi:10.1017/S0144686X08008167.

Headey, B. (2010). The set point theory of well-being has serious flaws: On the eve of a scientific revolution? Social Indicators Research, 97(1), 7-21. doi:10.1007/s11205-009-9559-x.

Howell, R. T., \& Howell, C. J. (2008). The relation of economic status to subjective well-being in developing countries: A meta-analysis. Psychological Bulletin, 134(4), 536-560. doi:10.1037/0033-2909. 134.4.536.

Inglehart, R., Foa, R., Peterson, C., \& Welzel, C. (2008). Development, freedom, and rising happiness a global perspective (1981-2007). Perspectives on Psychological Science, 3(4), 264-285. doi:10.1111/j. 1745-6924.2008.00078.x. 
Inglehart, R., Mcintosh, D., \& Pacini, R. (1992). Value priorities and religiosity-an empiric investigation. International Journal of Psychology, 27(3-4), 304-304.

Jung, J. H. (2014). Religious attendance, stress, and happiness in South Korea: Do gender and religious affiliation matter? Social Indicators Research, 118(3), 1125-1145. doi:10.1007/s11205-013-0459-8.

Kahneman, D., \& Deaton, A. (2010). High income improves evaluation of life but not emotional well-being. PNAS Proceedings of the National Academy of Sciences of the United States of America, 107(38), 16489-16493. doi:10.1073/pnas.1011492107.

Kim-Prieto, C., \& Diener, E. (2009). Religion as a source of variation in the experience of positive and negative emotions. Journal of Positive Psychology, 4(6), 447-460. doi:10.1080/17439760903271025.

Knight, J., \& Gunatilaka, R. (2010). The rural-urban divide in China: Income but not happiness? Journal of Development Studies, 46(3), 506-534. doi:10.1080/00220380903012763.

Levin, J. (2013). Religion and mental health among Israeli Jews: Findings from the SHARE-Israel study. Social Indicators Research, 113(3), 769-784. doi:10.1007/s11205-012-0113-x.

Linley, P. A., Maltby, J., Wood, A. M., Osborne, G., \& Hurling, R. (2009). Measuring happiness: The higher order factor structure of subjective and psychological well-being measures. Personality and Individual Differences, 47(8), 878-884. doi:10.1016/j.paid.2009.07.010.

Lobao, L., \& Hooks, G. (2003). Public employment, welfare transfers, and economic well-being across local populations: Does a lean and mean government benefit the masses? Social Forces, 82(2), 519-556. doi:10.1353/sof.2004.0016.

Lun, V. M. C., \& Bond, M. H. (2013). Examining the relation of religion and spirituality to subjective wellbeing across national cultures. Psychology of Religion and Spirituality, 5(4), 304-315. doi:10.1037/ A0033641.

Lutz, A., Brefczynski-Lewis, J., Johnstone, T., \& Davidson, R. J. (2008). Regulation of the neural circuitry of emotion by compassion meditation: Effects of meditative expertise. PLoS ONE, 3(3), 1-10. doi:10. 1371/journal.pone.0001897.

Lyubomirsky, S., \& Layous, K. (2013). How do simple positive activities increase well-being? Current Directions in Psychological Science, 22(1), 57-62. doi:10.1177/0963721412469809.

Masud, J., \& Haron, S. A. (2008). Income differences among elderly in Malaysia: A regional comparison. International Journal of Consumer Studies, 32(4), 335-340. doi:10.1111/j.1470-6431.2008.00674.x.

McCullough, M. E., Emmons, R. A., \& Tsang, J. A. (2002). The grateful disposition: A conceptual and empirical topography. Journal of Personality and Social Psychology, 82(1), 112-127. doi:10.1037// 0022-3514.82.1.112.

Metzl, E. S. (2009). The role of creative thinking in resilience after hurricane Katrina. Psychology of Aesthetics, Creativity, and the Arts, 3(2), 112-123. doi:10.1037/a0013479.

Miller, G. A., \& Chapman, J. P. (2001). Misunderstanding analysis of covariance. Journal of Abnormal Psychology, 110(1), 40-48. doi:10.1037//0021-843X.110.1.40.

Miret, M., Caballero, F. F., Chatterji, S., Olaya, B., Tobiasz-Adamczyk, B., Koskinen, S., et al. (2014). Health and happiness: cross-sectional household surveys in Finland, Poland and Spain. Bulletin of the World Health Organization, 92, 716-725. doi:10.2471/BLT.13.129254.

Mochon, D., Norton, M. I., \& Ariely, D. (2011). Who benefits from religion? Social Indicators Research, 101(1), 1-15. doi:10.1007/s11205-010-9637-0.

$\mathrm{Ng}$, W., \& Diener, E. (2014). What matters to the rich and the poor? Subjective well-being, financial satisfaction, and postmaterialist needs across the world. Journal of Personality and Social Psychology, 107(2), 326-338. doi:10.1037/a0036856.

Pew_Research_Center. (2015). Religion and public life: Data and resources from Pew Research Center http://www.pewforum.org/data/.

Rozer, J., \& Kraaykamp, G. (2013). Income inequality and subjective well-being: A cross-national study on the conditional effects of individual and national characteristics. Social Indicators Research, 113(3), 1009-1023. doi:10.1007/s11205-012-0124-7.

Sahraian, A., Gholami, A., Javadpour, A., \& Omidvar, B. (2013). Association between religiosity and happiness among a group of Muslim undergraduate students. Journal of Religion and Health, 52(2), 450-453. doi:10.1007/s10943-011-9484-6.

Senf, K., \& Liau, A. K. (2013). The effects of positive interventions on happiness and depressive symptoms, with an examination of personality as a moderator. Journal of Happiness Studies, 14(2), 591-612. doi:10.1007/s10902-012-9344-4.

Smith, R. L., Ager, J. W., \& Williams, D. L. (1992). Suppressor variables in multiple-regression correlation. Educational and Psychological Measurement, 52(1), 17-29. doi:10.1177/001316449205200102.

Snijders, T. A. B., \& Bosker, R. J. (2012). Multilevel analysis: An introduction to basic and advanced multilevel modelling. London: Sage.

Stata. (2013). Stata 13.1 statistics/data analysis. Texas: Stata Press. 
Stiglitz, J. E., Sen, A., \& Fitoussi, J.-P. (2009). Report by the commission on the measurement of economic performance and social progress. Paris: INSEE.

Tewari, S., Khan, S., Hopkins, N., Srinivasan, N., \& Reicher, S. (2012). Participation in mass gatherings can benefit well-being: Longitudinal and control data from a North Indian Hindu pilgrimage event. PLoS ONE, 7(10), e47291. doi:10.1371/journal.pone.0047291.

Torres-Reyna, O. (2014). Multilevel analysis (ver. 1.0). Retrieved from http://www.princeton.edu/ otorres/ Multilevel101.pdf.

Tovar-Murray, D. (2011). The multiple determinants of religious behaviors and spiritual beliefs on wellbeing. Journal of Spirituality in Mental Health, 13(3), 182-192. doi:10.1080/19349637.2011.593405.

UNDP. (2015). Human development index (HDI). New York: United Nations Development Programme (UNDP).

Veenhoven, R. (2008). Sociological theories of subjective well-being. In M. Eid \& R. J. Larsen (Eds.), The science of subjective well-being (pp. 17-43). London: The Guilford Press.

Wells, C. R., Probst, J., McKeown, R., Mitchem, S., \& Whiejong, H. (2012). The relationship between work-related stress and boundary-related stress within the clerical profession. Journal of Religion and Health, 5l(1), 215-230. doi:10.1007/s10943-011-9501-9.

World-Bank. (2015). GDP per capita (current US\$). Retrieved from http://data.worldbank.org/indicator.

World-Values-Survey. (2015). 1981-2014 Longitudinal aggregate v.20150418. Retrieved from www. worldvaluessurvey.org.

Wright, S. P. (1992). Adjusted P-values for simultaneous inference. Biometrics, 48(4), 1005-1013. doi:10. $2307 / 2532694$. 